\title{
From the Ordinary to the Concrete: Cultural Studies and the Politics of Scale
}

\section{Anna McCarthy}

Cultural studies in the 1990s has begun to forget its commitment to ordinariness

as a positive civic goal. (Hartley, 1999: 16)

The word scale is a complex and highly abstract noun that expresses a number of different kinds of proportional relations, from the comparative size of physical phenomena to the mathematically calculable relationship between an object and its representation. Because the concept of scale is so abstract and far ranging, this essay violates some first principles of composition and begins with dictionary definitions, elaborating the history of scale's usage in the human sciences. It will become apparent through this brief survey that although scale does not appear in Raymond Williams's Keywords, it certainly qualifies for keyword status. The problems of its definition, in other words, are "inextricably bound up with" the problems it is trying to describe (1976: 13). Exploring this conceptual richness and ambiguity, the following essay asks what the concept of scale means for methodology in cultural studies. Although the word is not a common one in cultural studies research, I will propose that a politics of scale has historically motivated cultural studies' interventions in the way knowledge is produced in the disciplines and spaces of higher education. As a political movement among intellectuals who are located within a variety of fields of inquiry, as well as in other institutions such as the arts and government, cultural studies has been defined by research agendas that vary widely from region to region as well as historically, in response to particular social conditions inside and outside the academy. However, it has consistently and persistently called attention to the 
broader political implications of scale-based methodological problematics such as the relationship between micro and macro social processes, or the establishment of valid conditions for empirical generalizability. Issues of scale, cultural studies research demonstrates, not only shape the forms and objectives of knowledge production but also serve as connections between intellectual activity and other forms of social practice. In giving readers an account of how the "problem" of scale, whether explicitly called that or not, has shaped descriptive terminologies and research programs within cultural studies, this essay offers a set of touchstones for evaluating how politicized work in the academy might find ongoing value in thinking about its agendas in terms of scale.

According to the second edition of the Oxford English Dictionary (1989; all references hereafter refer to the unpaginated online version) the first uses of the noun scale as a methodological concept appear in early modern taxonomy. They derive from the word's third meaning, the Middle English word for ladder, which endures in its current usage as a verb meaning to climb. The word's musical application, first documented in the sixteenth century, derives from this usage. In the early seventeenth century, a burst of usages associated with hierarchies of knowledge, abstraction and representation emerge out of this root meaning. By the seventeenth century, scale became conceived as a material idea akin to climbing a ladder into a new kind of service: as a model for conceptually rendering orders of being. This posits scale as "a succession or series of steps or degrees; a graduated series, succession, or progression; esp. a graduated series of beings extending from the lowest forms of existence to the highest" (OED, 1989: def 5a). Its earliest illustration is from Francis Bacon's 1605 Of the Advancement of Learning: "the speculation...That all things by scale did ascend to vnitie" (1605, quoted in OED, 1989). Here we have scale referring to the kind of metaphysical hierarchy, culminating in some kind of plenitudinous unity, which Foucault (1970) identified in the taxonomic procedures of early modern human sciences.

At around the same time, the word scale also begins to express quantified and exact relations of proportion. Usages dating back to 1607 define the term as referring to "relative or proportionate size or extent; degree, proportion" (OED, 1989: def. 12a). This definition, bringing the mathematical operations of the ratio into play, assigns an additional kind of systematicity to the idea of scale as hierarchical order. If Bacon's 1605 usage makes scale an expression of where things or 
beings are located on some predetermined metaphysical ladder, bringing proportion into the picture makes it possible to do away with the ladder entirely. Scale as proportion allows an observer to grasp something's significance simply by comparing it to other things, without reference to external standards of judgment. This ratio-based sense of scale expanded over the course of the seventeenth century to include quantified relations between objects and their representations. This development, which seems closely linked to the direction of political thought in the seventeenth century, defines scale as "the proportion which the representation of an object bears to the object itself" (OED, 1989: def. 11a). From this definition is derived the adjectival expression to scale, referring to a rendering "with exactly proportional representation of each part of the model" (OED, 1989: def. 11a).

This definition of scale as proportional representation might be thought of as a Big Moment, for it has clear implications for the production of knowledge, specifically, in relationship to the rise of empiricism. In proportional representation, relations between the referent and the sign are exact and quantified. The sign is a faithful reproduction of some key aspects of the referent (its proportions) and thus may be treated as identical to the referent in certain circumstances. This is the principle of scale in cartography, and, indeed, all of the examples supplied with this definition are cartographic, starting with a 1662 reference to a map of London. Relations of scale, this definition proposes, are relations that can be relied on because they are mathematically derived, thus guaranteeing a stable relationship between the representation and the real. This stability provides a model for empirical knowledge, in that the possibility of finding a mechanism of translation, or mapping, which connects material things and their representations in a precise, repeatable, and empirically known relationship extends to the process of representation in thought.

However, simultaneous usages of the concept of scale, extending beyond the mathematic applications and into the subjective realm of judgment and analysis, point to the methodological conundrum that scale continues to introduce into the research process. Early modern usages of scale as "a standard of measurement, calculation, or estimation" (OED, 1989: def. 13) apply not only to physical appraisal but also to the process of reasoning, specifically, to the conditions under which reason can move from the particular to the universal. The OED offers as an example of such usage a statement about methodology from Bacon's 1626 Sylva Sylvorum, or A Naturall Historie: "Definite Axiomes 
are to be drawn out of Measured Instances; And so Assent to be made to the more Generall Axiomes, by Scale" (cited in OED, 1989: def. 13). Here, the concept of scale helps stabilize a necessarily murky dichotomy: the relationship between physical observation and mental speculation in inductive reasoning. Bacon uses scale to explain how theoretical propositions are derived, showing them to be large-scale syntheses of smaller, discrete empirical phenomena. To earlier uses of scale as an expression of orders of hierarchy (the ladder) and relations of proportion (the map) this methodological proposition adds the far more complicated idea of scale as an expression of relations between physical specificity and theoretical generality, in other words, as degrees on a conceptual continuum spanning from materiality on one end to abstraction on the other. In constructing a thread between the two, scale regularizes the process of knowledge production by implying that there is a proportional relation between the datum, the definite axiom, and the general axiom.

With this final sense of scale as, in a sense, a conceptual pathway between the physical and the mental, early modern uses of the word solidify its current power as a methodological precept. Scale becomes a concept capable of managing dichotomies in multiple epistemological dimensions, disciplining the production of knowledge by regularizing procedures of physical measurement, quantified representation, qualitative evaluation ("order of being"), and intellectual abstraction. But this very elasticity is also a liability. Bacon's explanation of inductive method is interesting for the way it illustrates the slipperiness of scale as a technique of dichotomy management. In this statement, he manages to asserts the existence of universals (Generall Axiomes) while simultaneously acknowledging the necessity of convention and arbitrariness, if only rhetorically: it is the cultural, indeed electoral, process of "assent" that forges the metonymic connection between "Generall Axiomes" and "Definite" ones, and a metaphorically physical process ("drawing out") connects the latter to the measured, empirical world. Bacon's statement implies no definite break between the material world and consciousness, between particulars and universals, the concrete and the abstract. Although it might distinguish them from each other, it simultaneously offers the scale-based reasoning of induction as a thread of action and rhetoric actively connecting thought and thing, observation and speculation. This makes orders of scale seem fundamentally arguable, always open to judgment and dependent on relativism. 
From this etymological excursion it should be clear that while decisions based on judgments of scale are clearly central to methodological conventions in modern intellectual inquiry, these procedures seem entangled and slippery when we consider them closely. The kinds of relationships designated by scale go beyond the simple physical sense of size. They straddle the qualitative/quantitative divide, enabling conceptual movement between argument and evidence, generality and specificity, concreteness and abstraction. It is because of this slipperiness that orders of scale perform so many basic epistemological tasks within the modern apparatuses of knowledge production within the academic disciplines. Taken individually, the various methodological procedures that organize research through scale are crucial for managing uncertainties about how to link conceptual and/or material objects that are of different degrees of size and abstraction. Orders of scale establish standards and priorities in research. Conceptions of appropriate scale determine the limits of case studies. They carve up research agendas in space and time, in relationship to geographical regions and temporal periodization. Less obviously, a sense of scale shapes relations between primary and secondary materials - a relation which is not only temporal, as the terms imply, but also a relationship between two conceptual scales: the particular and the general. They establish fields and subfields of inquiry (e.g. micro- and macroeconomics), and they help distinguish between theory and method in empirical research. E.P. Thompson's words are exemplary here: "methodology is [sometimes] used in place of theory. [But] there is such a thing as methodology, which is the intermediate level at which a theory is broken down into the appropriate methods you are going to use ...to test that theory, and equally at which empirical findings are brought up to modify the theory" (1984: 14). Thompson's use of the term level to describe these forms of abstraction and generalization indicates the persistence of Bacon's schema in locating theory in a conceptual relationship to observation and recording. It implies that what might be called the "general axioms" of theory are formed from what would correspondingly be the "specific axioms" of method. It is a relationship in which method is at once the elemental "stuff" out of which theory is formed and, in its specificity, something fundamentally other to theory.

An order of scale also plays a key role in defining terms within methodology; specifically, it manages the distinction between method and technique. The latter term, two historians note, refers to the routine processing of evidence (note-taking, counting, etc.), whereas method 
defines the more general process of reflection upon conditions of knowledge production (Karsten and Modell, 1992: 1-2). Orders of scale are thus active in defining methodological problems within and across the disciplines. Historians, literary critics, sociologists, biologists, and economists must all endeavor to reconcile the different levels on which their research proceeds, balancing the scope of their conclusions with the size of their data, and articulating the kinds of knowledge that are enabled by the range of their research.

As this might suggest, orders of scale also provide the disciplines with a ready-made framework within which to launch a critique of particular research projects. Whenever a project's methodology deviates from conventional scales of analysis, it can be disciplined, corrected, and even discounted through appeals to the kinds of evidence that are produced on other scales of analysis. You can attend a panel of world system historians in the morning and chide them for the absence of "voices" in their accounts, and then criticize a panel of ethnomethodologists and microhistorians for disregarding the big picture in the afternoon. In each instance, what you are calling for is an impossible thing: a research stance that affords a total view, and which is able to move effortlessly between scales. You are asking, in other words, for a researcher who embodies the ideal liberal subject, capable of synthesizing all forms of knowledge, and a research program capable of absorbing all epistemological perspectives (Tinkcom, 2002). Thus Peter Burke, questioning the value of microhistory's "human interest stories," calls for historians to "link the microsocial and the macrosocial, experiences with structures, face-to-face relationships with the social system or the local with the global. If this question is not taken seriously, microhistory might become a kind of escapism, an acceptance of a fragmented world view rather than an attempt to make sense of it" (Burke, 2001: 116-17). It should be noted that this desire for an impossible holism is not limited to the viewpoints of professional historians. In sociology, Randy Martin notes, the quest for totality is evident in the Parsonian legacy: "For the system-theoretic model, [the ethnomethodologists'] alternate sociologies were relegated to occupying the place of the micro in the very syntax they were meant to disturb" (2001: 65). Functionalism, with its smoothly working scale models of the social world, thus serves as a kind of disciplinary superego, generating rote critiques that make it impossible for the "local" simply to be local - it has to be situated as typical, or not typical, of some kind of non-local, non-concrete phenomenon. 


\section{Orders of Scale in Cultural Studies}

Having laid out the origins of scale as a methodological concept and sketched some of its currently central functions in methodological thought and debates within the disciplines, I want to turn to what the concept means for cultural studies. But first this means asking what methodology might mean outside of a disciplinary context, within an intellectual movement responsive primarily to political conditions both within and outside the academy, and only secondarily to the protocols for the production of knowledge that are established within conventional fields of research. If the construction of a method, regardless of disciplinary status, is part of all research and, moreover, if all research necessarily involves selections and assessments based on orders of scale, then what guides these procedures within cultural studies? I will argue in this section, assuming the leftist agenda that has historically defined cultural studies as a movement, that these procedures are - indeed should be - guided by particular political considerations. And, moreover, I will suggest, the complexity of scale as a concept makes it a particularly rewarding way of defining methodological interventions in the disciplines from outside. The slippery relativism of orders of scale always open to the possibility of adding one more degree of size or magnification, one more level of concreteness or abstraction, always producing continuities between things and ideas, between universals and the particulars that produce them - makes them highly heuristic thinking tools for cultural materialists. ${ }^{1}$

On a very general level, you can observe the consistence presence of a politics of scale in cultural studies' agenda-setting across the broadest of disciplinary breaks, disciplinary contexts, and "generational" arguments. A basic suspicion of generalized abstractions is one of the most obvious connections, although it is also an intellectual tendency that leads to the occasional conflation of cultural studies and postmodernism in North America. This suspicion is evident in one of Raymond Williams's most frequently cited dictums: pedagogically invaluable for media studies teachers, that "There are in fact no masses; there are only ways of seeing people as masses" (1958: 300). It is equally present in Marianne de Laet's assertion that the anthropology of science and technology shares with cultural studies a commitment to "tracing how, exactly, particulars become universals" (2001: 101). However, the politics of scale in cultural studies' methodological debates goes beyond 
antifoundationalism. In the realm of critique, a concern with the power relations of scale is evident both in those attacks on cultural studies projects from outside, and in those aimed at modifying them from the inside. In the latter camp, Austral and non-Western cultural studies scholars note that their work is governed by a "West and the rest" geopolitics. Thus, for example, doing cultural studies in Hong Kong means ignoring one's local audience in favor of an accrediting international and universalized English-language readership (Ma, 2001: 271). A similar orientation toward non-local readerships means that Australian cultural studies must engage generalized theoretical constructs like "“difference,' 'pleasure,' 'subversion,'” rather than studies of national media texts in order to avoid being "pushed for methodological reasons into the 'dead zone' of the too specific ..." (Morris 1992: 457, original emphasis. See also Grossberg, 1997: 298). Meanwhile, Occidental critics charge that cultural studies celebrates the local, fetishizes the specific, and exaggerates the power of the individual at the expense of other, structural forces, like economic oppression (Garnham, 1995; Maxwell, 2001). The debate is endless; feminists (rightfully) rejoin with the provocation that perhaps masculinist visions of totality make critics unable to see the forms of noncapitalist activity that define people's everyday movements through capitalism (Gibson-Graham, 1996). For those who see the choice between political economy and cultural studies as an "either/or" one, the two movements are irrevocably divided by axiomatic differences in the scale on which they construct models of social change.

The various critiques of cultural studies as having an inappropriate sense of scale clue us into some differences between methodology within cultural studies and methodology in the disciplines. These differences are important: if Dennis Dworkin's excellent and appreciative history of British cultural studies must repeatedly offer a cautionary criticism of various researchers' apparent refusal, or inability, to generalize, then clearly some things need to be set straight (1997: 84-5, 162, 189). One way to think about the difference is to say that, within disciplines, methodology is formed not only to govern and reflect upon the production of knowledge, but also to police entry and enforce sometimes reactionary notions of "standards" in the service of "pure" knowledge production (Miller, 2001). The "threat" of cultural studies is its disrespect for disciplinary orthodoxy. Not being a discipline, cultural studies does not have the same kinds of standards to police (which is not the same thing as saying that it is incapable of surveillant or 
disciplinary acts). But if it aims at producing provisional, rather than eternal knowledge (Nelson et al., 1992: 6) this does not mean that cultural studies has no method, as is sometimes claimed (ibid.: 2). Indeed, its practitioners have regularly engaged in debates over particular methods, for example, the value of "cultural critique" versus "cultural policy." Indeed, it has seemed at times that debates leading to programmatic statements about the direction of the field have been the most visible work in cultural studies. Clearly, cultural studies has a long history of methodological thought. But what distinguishes its methodological reflection from more disciplinary ones?

The difference becomes evident when we contrast a disciplinary approach to orders of scale, such as Burke's previously cited critique of microhistory as merely "human interest stories," with one delineated in cultural studies. A good example of the latter is the explicit discussion of methodology and scale in Stuart Hall's famous "Two Paradigms" essay (1980). The essay intervenes in the argument between the empiricist, micro-oriented, resistance-minded "culturalists" (e.g. Thompson and Williams) and the "structuralists" (theoretical, anti-empiricist, Althusserian) that took place in the 1970s. These arguments are largely about scale and determination in Marxist models of culture, binarized as a choice between commitments: to theory and to structural explanation on the one hand, to empirical research and careful analysis of practices on the other. For Hall, this is a false dichotomy. Cultural studies' mission is not to choose one or the other, but rather to follow a Gramscian path and attempt "to think both the specificity of different practices and the forms of the articulated unity they constitute" (Hall, 1980: 72). Now it might seem that here Hall constructs a methodological model, based on the synthesis of different scales, structurally comparable to the liberal subject's totalizing viewpoint articulated by Burke. But whereas Burke assumes the existence of the "macro" as an actual, material level of the social, Hall's model characterizes the macro-level - the totality - not as a material entity, but as a form of abstraction.

Hall bases this model on Marx's dialectical method in Capital, articulated in a quote, apparently from the Grundrisse: "In the analysis of economic forms, neither microscopes nor chemical reagents are of assistance. The power of abstraction must replace both" (67-8). In his exegesis of Marx's method, Hall introduces two metaphors for the viewpoint of the cultural studies researcher: the microscope and, more implicitly, the map. Note that in the quotation above, Marx invokes 
the microscope's material process of visual scale manipulation in opposition to the mental process of abstraction. Hall's analysis, however, twists this opposition into an analogy. Marx's method, he notes,

rests not on the simple exercise of abstraction but on the movement and relations which the argument is constantly establishing between different levels of abstraction: at each, the premises in play must be distinguished from those which - for the sake of argument - have to be held constant. The movement to another level of magnification (to deploy the microscope metaphor) requires the specifying of further conditions of existence not supplied at a previous, more abstract level: in this way, by successive abstractions of different magnitudes, to move towards the constitution, the reproduction of "the concrete in thought." (68, emphasis in original)

Whereas Marx referred to the empirical process of observation associated with microscopy as an illustration of what the process of dialectical abstraction is not, Hall transforms the optical process of moving between different levels of magnification into an analogy for the dialectical method.

Hall compounds the metaphorical reversal by invoking a different sense of scale immediately after citing Marx's microscope. This is his restatement of the goal of the dialectical method as the "reproduction of the concrete in thought." This phrase compares dialectical analysis not to shifts in perspective achieved through optics, but rather to the process of representation or creative activity, via the notion of "reproduction." Hall's proposal for a unified cultural studies is based on relationships of scale insofar as its invocation of the concrete implies that the final product of the dialectical method is something like the perfect - and impossible - map, a map which aims at the reproduction of a terrain at a scale of $1: 1$. Hall thus explains the simultaneous necessity and contingency of abstraction by comparing it on the one hand to the idea of optical scale, shifted by lenses placed between subject and object, and on the other hand to the idea of representational scale, the proportional reproduction of an object.

What's important here is the way Hall's twist on Marx's microscope makes abstraction a material process of scale manipulation on a par with optics and proportional representation. His inversion of Marx's metaphor might therefore be thought of not simply as an attempt to render a difficult concept easier to grasp, but also as an attempt to synthesize another key insight from the Grundrisse, 
namely, Marx's radically relativizing assertion that abstraction is always a material production: "[E]ven the most abstract categories, despite their validity - precisely because of their abstractness - for all epochs, are nevertheless, in the specific character of the abstractions, themselves likewise a product of historic relations, and possess their full validity only for and within these relations" (1973: 105). In other words, nothing is transcendent for all time. Abstractions (and, by extension, expressions of concreteness) are historically rooted and thus variable from epoch to epoch.

Together with the material processes invoked in the metaphors of microscope and 1:1 map, as ways of manipulating the concrete through abstraction, this radically relativizing and historically contingent understanding of what stands as "generality" - indeed, as theory - signals the difference between cultural studies' methodological commitment to moving between macroanalytic and microanalytic scales and the meaning of this analytical movement in the disciplines (a meaning I am admittedly singularizing by using Burke as its straw man). In the latter, scale shifting is understood as the reconciliation of different, but equally stable and consistent levels of empirically derived knowledge about the social. It is the correct procedural technique for the production of the researcher as knowing liberal subject. In this context, it is hardly coincidental that particularly influential micro-methodological interventions in the disciplines, like Carlo Ginzburg's The Cheese and the Worms (1980), take as their subject matter the historical conditions under which particular, subjective models of abstraction (i.e. Menocchio's cosmology) are formed (on this point cf. Foucault, 1970). In cultural studies at the moment Hall is describing it, scale shifting is understood not as a movement toward greater positivist knowledge but rather as an acknowledgment of the limits of all knowledge claims, their grounding in particular material circumstances, mediating technologies, and metaphors. Moving between levels of abstraction is a way of relativizing knowledges, revealing their origins in particular material conditions, not of striving toward all knowingness.

This might sound like a reduction of cultural studies to antifoundationalism or postmodernism, but there are important differences. What Hall is attempting to articulate for cultural studies is a politicized understanding of social totality on which to base a research methodology. He therefore refuses a Foucauldian model of concreteness for cultural studies on the basis of a commonly held assessment of Foucault's epistemological position: "Foucault so resolutely suspends 


\section{Anna McCarthy}

judgment, and adopts so thoroughgoing a skepticism about any determinacy or relationship between practices, other than the largely contingent, that we are entitled to see him ... as deeply committed to the necessary non-correspondence of all practices to one another. From such a position neither a social formation, nor the state, can be adequately thought" (71). As this last sentence might suggest, Hall's commitment to the development of "a properly materialist theory of culture" lies in the need to understand culture in terms that might expand forms of social praxis. He opposes this to Foucault's project, although the recent applications of Foucault's later work on governmentality - a literature I will address presently in relationship to the cultural policy "push" in cultural studies - points to an area of significant overlap. Indeed, it is interesting to note that both Hall and Foucault were grappling with neoliberalism's ascendancy at the same moment in the late 1970s.

Cultural studies' broader commitment to political practice is evident in its commonplace characterization as an antidisciplinary formation, guided by progressive left politics rather than knowledge production. The methodological implications of this point are elaborated in Jennifer Darryl Slack's proposition that "the commitment is always to be able to adapt our methods as the new historical realities we engage keep also moving down the road" (Slack, 1996: 114). Method, this suggests, might better be thought of in terms of knowledge and theory production oriented toward a debate, or consensus, about what the left needs to know about culture at a particular moment; it is a particular way of relating theory to praxis. A well-known passage from Engels describes praxis as the goal of theory because, after all, "the proof of the pudding is in the eating"; moments of methodological reflection might therefore best be understood as ways of devising recipes for the pudding of praxis, however it is defined at the time. This "peculiar condition" has led to the characterization of cultural studies' method as a changing bricolage of self-reflexive techniques. Indeed, Lawrence Grossberg suggests that cultural studies "has to be made up as it goes along. Thus cultural studies always reflects on and situates itself and its claims, limits its field, acknowledges its incompleteness" (1997: 285. See also Willis, 1980: 95).

This is a useful definition of cultural studies' methodological improvisation, but there is a certain idealism in the image of "making it up as we go along." This image can only stand for methodology in a very abstract, un-institutional sense, projected outside of the messy, fraught 
context of professional norms and power relations in higher education. The key word in Stuart Hall's proposition that cultural studies took shape in Birmingham as an institutional practice "that might produce an organic intellectual" (1992: 281) is surely produce, as it calls attention to the material conditions of academic work, conditions which, as Grossberg notes elsewhere in a discussion of the Americanization of cultural studies, bring cultural studies into alignment with complex problems of professionalization, academic class politics, and disciplinary "turf" (1997: 297-8). Thus, although the improvisatory model may accurately describe the ideal conditions of research in cultural studies, namely its responsiveness to political questions of the moment, any attempt to account for shifts in the methodological horizons of cultural studies must emphasize not only how such shifts have emerged from particular historical and political circumstances (e.g. Thatcherism), but also how they have followed a logic of autocritique within the movement and in some kind of interaction with the disciplines. ${ }^{2}$ Although the process of recognizing, querying, and building on an intellectual history and an institutional trajectory may not be as coherent, evolutionary, or authorized as it seems to be within disciplines, it is nevertheless part of the movement of cultural studies. Methodological shifts in cultural studies, at least those oriented around problems of scale, can definitely be tracked as responses to existing research agendas, and ongoing systems for valuing and accrediting the work of professional academics. ${ }^{3}$

With this in mind, the next section of this essay traces some of the ways cultural studies has sought to politicize academic knowledge, and frame politics outside the academy, by scrutinizing the power relations encoded in conventional orders of scale within which this knowledge is produced. The threatening unmanageability of scale as a concept means that I will only address one thread of its emergence in cultural studies: the formation of, and crisis in, "ordinariness" as a research topic. The crisis must be seen as continuous with the political commitments of postwar British intellectuals that led to the emergence of the ordinary in the first place, interests which shifted the focus of discussions of culture from the idea of a pure and abstract good to the concrete and material frame surrounding such abstractions. "Ordinariness," like Marx's abstraction, is historically specific; what gets counted as ordinary can shift radically over time. As Charlotte Brunsdon notes, reflecting on the legacy of the work in television studies conducted at Birmingham in the 1970s, "ordinariness has 
unquestionably changed" (2001: 57). However, as I will suggest, even though what counts as "ordinary," and "concrete" or as "exceptional" and "abstract" is different in each case, one can nevertheless discern an ever-increasing insistence on the inescapably material conditions of knowledge production in the discussions that constitute cultural studies across a range of arenas.

\section{Ordinariness in British Cultural Studies}

"Ordinariness" is arguably the first attempt of cultural studies to manipulate disciplinary assumptions of scale in order to call attention to particular political goals. In their writings in the 1950s and 1960s, Richard Hoggart, E.P. Thompson, Williams, and other New Left cultural critics, historians, and sociologists fashioned ordinariness into a deliberately small-scaled conceptual object that was not only to be studied but also lobbed over the walls of the disciplines and institutions of higher learning. Ordinariness is an abstract noun, but what it designated in the early days of cultural studies was, in some ways, the embodiment of concreteness: the sediment of practices that make up everyday life on the small scale of lived experience. However, ordinariness is also incredibly large scale. As a concept, its place within a managed dichotomy is marked out in opposition to the extraordinary, the remarkable, the special, the valuable; if the latter are scarce, rare, and "out of the ordinary" phenomena, then the ordinary is a resource in abundant supply. But, paradoxically, it is so immediate and ubiquitous that it is also invisible, ineffable, ephemeral. As a concept, ordinariness thus served a political purpose within academic research programs by disrupting conventional assumptions about scale and value, generality and importance. The paradoxical orders of scale contained and defined within the concept of the ordinary were, for the postwar British intellectual left, endemic to the material analysis of culture. As Williams wrote, in Culture and Society, "the difficulty about the idea of culture is that we are continually forced to extend it, until it becomes almost identical with our whole common life" (1958: 256).

In some respects, analyzing ordinariness might seem comparable to analyzing "the everyday;" as Luce Giard notes in relation to the latter, it "is doomed to an incessant coming and going from the theoretical to the concrete and then from the particular and circumstantial to the general" (1998: xxiii). However, there is a crucial difference between 
the French legacy of the everyday and ordinariness in early British cultural studies. In the latter, the commitment to the concrete experience of the ordinary erupts from working-class politics and demands for the redistribution of cultural capital in higher education, whereas the French Situationist everyday and its afterlives expresses more diffuse political commitments, arguably more bourgeois, undoubtedly more avant-gardist. Ordinariness in early British cultural studies reflects a desire to speak about working people's lives, necessarily lived in local contexts, and the ways in which individual biographies add up to class trajectories, helped or hindered by particular institutions for the dissemination and consumption of culture. This desire becomes immediately clear to anyone who pages through volumes of Universities and Left Review from the 1950s. One encounters a striking array of articles, documentary photo-essays, and film and television reviews oriented around questions of changes in the institutions and experiences of everyday working-class life in postwar Britain. This interest reflects political and intellectual questions being asked on the left in this period, as a response to social conditions within and outside of the academy, among them apparent forms of class mobility opened up by consumption, shakeups in international socialism, and the intellectual maturation of a new generation of working-class scholars (on these factors, see Dworkin, 1997: 1-124). From within the latter group, both Williams's pronouncement that "culture is ordinary" and Hoggart's 1957 Uses of Literacy, described by Hartley (1999: 16) as a founding text in a "semiohistory of ordinariness," helped define the methodological "lowering" of sights from "high" to "ordinary culture" as a political gesture. According to Frank Webster, Hoggart's microscopic attention to detail and cadence distinguished the Uses of Literacy from sociological studies of working-class life: "you can hear the voices of flesh and blood people and feel their presence, you can be there in a way in which most Sociology sadly misses" (2001: 81, emphasis in original).

In the work of Hoggart, in particular, we can see a complex mediation between orders of scale, from micro to macro, to produce a concrete sense of working-class people's culture and their resources for survival. Like Ginsburg, Hoggart addresses issues of scale not only in his methodological framing but also in his subject matter, showing how the "macro" space of the nation is inaccessible to the working people of the North (a tactic Marx used to great effect in Chapter Ten of Capital, vol. 1). As Gibson and McHoul note, Hoggart's method was highly interdisciplinary. He essentially invented the "bricolage" method 


\section{Anna McCarthy}

of cultural studies, combining "literary studies, sociology, and autobiography;" to replace "big literary history" with "the detail of the little histories of ordinary life" (2001: 25, 23. See also Dworkin, 1997: 85). This mixture was not merely a set of choices made in the interests of rhetorical effect. It also reflected the institutional arrangements circumscribing the position from which he spoke - that of the scholarship boy, whose curious insider/outsider perspective made him a figure who could be taken "as standing for nascent cultural studies itself" (24-5). But Hoggart's mediated perspective does more than make possible a mobile narrative technique, moving easily from one scale of analysis to another to produce both textured renderings and distanced judgments. It also leads him into a discussion of orders of scale as expressions of material power. In a section of The Uses of Literacy (19) entitled "the personal and the concrete" he notes that working-class conceptions of "us" and "them" are founded in a lack of access to non-local scales of social experience: "The question of how we face 'them' (whoever 'They' are) is, at last, the question of how we stand in relation to anything not visibly and intimately part of our local universe" (72). For Hoggart, the worldview of his working-class neighborhood was premised on the impossibility of abstractions and translations in scale, such as "the needs of the state" or "good citizenship" (73). It took his own mobility through the British education system, and the class injuries incurred along the way, to gain a more "aerial" perspective, a perspective which included an awareness of the class-delineated horizons of abstraction, knowledge, and macro-level access within which bourgeois models of political life are formed. Hoggart's technique, incorporating his own travel between scales, thus embodies the kind of abstraction Hall identified, via the metaphor of the microscope and the 1:1 map, as cultural studies' dialectical mandate: reproducing the concrete in thought.

However, over the course of the next few decades, critiques within cultural studies as a movement would begin to question the politics of knowledge, the models of the social, and the assumptions about universal subjectivity that came to be encoded in the concept of ordinariness as advanced by Hoggart and others. Originally serving as a heuristic tool within higher education, forcing debate around hierarchies of culture, and calling attention to the ordinary people affected by these hierarchies, the ordinary itself became a problem, constructing hierarchical scales of its own. As cultural studies developed and institutionalized at Birmingham in the 1960s and 1970s, figures other than 
the scholarship boy came to stand for cultural studies, and wreak havoc with the "ordinary" on which its theories of culture rested. In the process, more diversified scales of analysis entered the cultural studies repertoire of methodologies, as expressed both in research projects at the Centre for Contemporary Cultural Studies (CCCS) and in its theory seminars.

Perhaps the first challenge to the ordinary came in the highly visible form of the youth cultures emerging in the 1960s and 1970s, cultures which, in their disaffection, marginality, and extraordinary forms of display fashioned in kinship and conflict with Black British style, placed pressure on self-evident, homogenous connections between workingclass culture and ordinariness. In the encounters between intellectuals and youth taking place in this period, new research models were formed. A renewed understanding of power relations and judgments of scale played an important role in their development. Youth cultures brought spectacular visibility and new forms of social collectivity onto the research agenda, raising new questions about the direction of working-class and national culture in Britain. In 1959, writing in the last issue of ULR, Hall proposed that "The revolt and iconoclasm of youth today arises because of the contradictions between the true and the false elements in their culture: because the wave of post-war prosperity has raised them to cultural thresholds which offer rewards unequal to the expectations aroused" (quoted in Hartley, 1992: 6). Youth culture, in this formulation, was one of many symptoms of working-class disappointment in the postwar promise of opportunity. To grasp these changes, researchers drew on small-scale research techniques, like ethnography and participant observation, to supplement the more formal interviewing techniques which had characterized earlier sociological experiments, like the ULR reports on life in "New Towns." These techniques kept the researcher on the same scale as his or her informants, so that no total "aerial" vision of cultural traditions could be gleaned. Thus, what Resistance Through Ritual (Hall and Jefferson, 1976) and Subcultures (Hebdige, 1979) produced was not a holistic vision of culture composed of layers of infinitesimal ordinariness, but a rather more complexly scaled vision of generational conflict, racial heterogeneity, and modes of cultural consumption within the homogenous designation of class. Ordinariness became a parental ideology, a tradition in crisis.

However, it would take interventions by feminists and scholars working on issues of race and ethnicity in British culture to fully 
demolish the rule of ordinariness, revealing the assumptions upon which it was based (Hall, 1992; see Brunsdon, 1996, on the problematic assumptions underlying narratives of the history of CCCS as a series of "interruptions" by feminism and black activism). Certain kinds of people's lives and cultural activities were coming to represent the ordinary at the expense of others, specifically women's activities. These ordinaries, it seemed, were simply too ordinary to capture the attention of researchers. Following feminist interventions in the Centre's research agendas, the "housewife" became the site of the thickly described, participatorily observed forms of ordinary culture with which cultural studies research was concerned. (On this figure, see Brunsdon, 1999. See also Dworkin, 1997: 176-80.) Around the same time, normative subjects and universals took on a different challenge, as scholarship on race and ethnicity within British cultural studies threw the entire centrality of the ordinary as an object of study into question. Ordinariness came dangerously close to the concept of Englishness, a form of exclusion emerging from historical conditions of empire and immigration. For some Britons, ordinariness was never an option. This scholarship reframed concerns with specificity and concreteness away from the routines of the ordinary and toward the ongoing crisis of race relations in Britain, a crisis formed at the end of the decade in the concurrence of Thatcher's victory and a series of incidents of uprising and racial violence (Dworkin, 1997: 180). In this climate of what Hall would later call "authoritarian populism," designations of ordinariness, of Englishness, of "we" became problematic concepts. They were revealed as ongoing expressions of power, marking some experiences as universal and others as specific and partial.

According to Hall (1992: 283), these interventions, and the "linguistic turn" prompted by continental theory, shaped the direction of methodological discussions at the CCCS under the direction of Richard Johnson in the second half of the 1970s. The (implicitly white, male) focus on the "ordinary" understood as the working-class culture gave way to complex, highly theoretical models of power and oppression, including racism and sexism, in which class struggle was only one of several factors. In methodological terms, this had several consequences. First, it brought other theoretical figures, like Fanon, into the pantheon of cultural studies (Stam, 2001). Secondly, it brought non-popular media forms into the conceptual orbit of cultural studies, specifically, the experimental film essays of the Black film collectives (Pines, 1996). And thirdly, by insisting on the historical specificity of race, "in order 
to see how it articulates - or not - with other social relations" (Solomos et al., 1982, quoted in Dworkin, 1997) scholarship on race and ethnicity made it impossible for models of culture to be structured according to simple hierarchies of significance, anchored in an economic "last instance." This insistence on specificity disrupted any easy identitarian equivalencies that might be made under terms like "women's history" (Carby, 1982/1996). Much as ordinariness had revealed the value systems of traditional approaches to culture in higher education a few decades earlier, these interventions on the level of race and gender exposed ordinariness as a concept that naturalized certain hierarchies of scale, rendering one kind of experience general, primary, and national and marginalizing others to the zone of the contingent and the specific in the process. Once a way of communicating materiality, ordinariness now worked to efface it.

\section{Post-ordinary Cultural Studies: Articulation and Policy}

What replaced ordinariness in British (or Anglophone) cultural studies? If the term represented a methodological insistence that the act of calling something or someone "ordinary" was a judgment of scale inseparable from social structures of class (or race and gender), the subsequent research agendas of cultural studies shifted the question of the politics of scale away from the ordinary and toward the more abstract concept of concreteness (this shift is embodied in the summary turn of Stuart Hall's 1980 "Two Paradigms" article). In the 1970s, an engagement with Gramscian theory and Althusserian structuralism led many on the culturalist side to articulate their sense of the politics of research in less historical, and more theoretical terms. However, questions of scale, in different ways, remained central to the research agendas that developed from this shift. Emblematic of the change is Raymond Williams's work following the "linguistic turn," in which the structural place occupied by ordinariness is now claimed by a theoretically-informed notion of materiality. Guided by a continued suspicion of abstractions, Williams's exemplary and influential discussion of base/superstructure models in Marxism and Literature (1977) offers a thoroughgoing critique of dichotomous theories based on a bourgeois distinction between the material and the immaterial. Williams found Gramsci's concept of hegemony vital as a way of thinking about 
how material life - institutions and practices of culture - served as an arena for domination and subordination (111). While acknowledging the contributions of Althusserian structuralism to marxist cultural theory, particularly the role of ideology in the reproduction of relations of production, Williams refused to see the base/superstructure relationship in Althusserian terms, that is, as an opposition between the material world and the world of ideas oriented toward the perpetuation of the relations of material production (93). Rather, everything is material; it is the designation of certain phenomena as non-material that is the characteristic ideological move of bourgeois philosophy. In an essay on the sociology of culture, Williams similarly criticized the "bourgeois concept of 'mass communication' and the tied radical concept of 'mass manipulation"" as "inadequate to the true sociology of these central and varying institutions" (136). Instead of the study of the diffuse psychological phenomenon of media effects, he advocated the study of "the complex sociology of [media] producers, as managers and agents within capitalist systems" (137). This emphasis on materiality maintained the focus on people that had initially brought ordinariness into the spotlight as a research topic. But now, following the "linguistic turn" in cultural studies, the people whose activities together comprise the institutions where culture is produced, rather than those who consume culture, defined Williams's sense of cultural materialism.

This turn toward cultural production anticipated the ideas about the politics of scale emerging in cultural studies' research agendas in this period, ideas that would implicitly reevaluate and reinterpret existing notions of the concrete, the ordinary, and the material in the movement. The two that I will examine here seem at first to be radically opposed to each other in their understanding of intellectual activism. One, the concept of articulation, extended cultural studies in a theoretical direction, whereas the other, cultural policy advocacy, eschewed theory in favor of administrative action. Both, however, sought to untangle the political meanings of concreteness. In reckoning with scale as an expression of degrees of materiality, these new directions in cultural studies may have challenged the underlying assumptions of ordinariness as a primary subject matter but they nevertheless maintained contact with the theoretical interventions previously done in its name. Like the small-scale, micro-level processes designated by the concepts of the ordinary and the popular, both the identity formations described by articulation theory and the practical, managerial work of cultural policy making sought to uncover the material origins of the 
abstractions generated by the idea of culture at a particular moment. In tracing the political meanings of methodology in both articulation and policy as materially oriented projects, this essay moves toward its concluding speculations on the ways that an awareness of the politics of scale might continue to serve as a valuable tool for intellectual activism whether or not it is carried out under the banner of cultural studies.

The theory of articulation inaugurated a methodological shift in cultural studies - from ordinariness to crisis, from class to multiple structures of difference. How might the social experiences and structuration of race and/or gender, and/or sexuality at a particular historical moment mediate and even determine political economy, researchers asked - acknowledging as much as possible the mutability of such categories as they emerged as forms of social knowledge. The theory of articulation was the solution. According to Jennifer Darryl Slack, articulation emerged as a model through which researchers in cultural studies might maintain a materialist perspective on culture for as long as possible, resisting overly reductive abstractions associated with existing Marxist concepts of culture and determination (Slack, 1996: 116). As Slack's genealogy of the term points out, articulation often served as a kind of placeholder for a non-reductive position in late 1970s and early 1980s British marxist discussions about culture, signifying the possibility of "theorizing the elements of a social formation and the relations that constitute it not simply as relations of correspondence ... but also as relations of non-correspondence and contradiction ..." (117). Issues of scale were implicit in all of these discussions, oriented as they often were around the Althusserian concept of "a complex totality structured in dominance ... made up of a relationship among levels" (ibid.). These discussions borrowed from Marx the idea that such relationships were not predestined by the mode of production but rather "produced within specific conjunctures [which] come to be seen as historically specific articulations of concrete social forces" (117). Hall, drawing on Ernesto Laclau and Antonio Gramsci, brought the model of articulation into cultural studies where he proposed it be understood as a particular kind of concrete process: "An articulation is thus the form of the connection that can make a unity of two different elements, under certain conditions. It is a linkage which is not necessary, determined, or absolute for all time. You have to ask, under what circumstances can a connection be made?" (1986 interview with Grossberg published in Morley and Chen, 1996: 141). 
For Hall, there were tangible stakes in his proposal of articulation as a methodological assumption for work in cultural studies. It was a concept that could disarm overly hierarchical models of power, not only those which placed relations of production at the prioritized top (or controlling bottom) of the scale, both as abstract structures operating on material life, if only at "the last instance," but also those which had placed a particular kind of (white, male) ordinariness at the vanguard of political change in cultural studies. In 1980, outlining the methodological principles ("theoretical protocols") that could be derived from the concept and which "must govern any ... proposed investigation" into the pressing phenomenon of racism under Thatcher, Hall prioritized "the premise of historical specificity" in which "racism is not dealt with as a general feature of human societies, but with historically specific racisms" (1980/1996: 50). Racism, in short, is an articulated structure in that it cannot be explained "in abstraction from other social relations" (51). Articulation thus set a methodological agenda for cultural studies in that it required, Hall noted, that research start "from the concrete historical 'work' which racism accomplishes under specific historical conditions - as a set of economic, political, and ideological practices, of a distinctive kind, concretely articulated with other practices in a social formation" (52).

The concept of articulation thus promised to re-order the orders of scale that had remained implicit in cultural studies' suspicion of universals, by making the temporally scaled down limits of "specific historical conditions" more central. And in its recognition of multiple intersecting practices, articulation seemed capable of transforming the materialist approach to culture into a flexible and historically responsive, and complexly scaled, theory of power. In the insistence on (pace Althusser) no necessary correspondence between "levels" of social life, and in the refusal to name stable causes and ultimate determinants a priori, the theory of articulation replaced both "vulgar" and "structuralist" Marxist explanatory paradigms with a Gramscian insistence on the concrete. As Hall notes, "Gramsci's work often appears almost too concrete; too historically specific, too delimited in its references, too 'descriptively analytic,' too time and context-bound" (1986/1996: 413). For Hall, the (Althusserian) critique of Gramsci as "untheorized" errs in mistaking the nature of Gramsci's debt to Marx. For while he certainly worked with key marxist concepts (mode of production, forces and relations of production), he recognized them as abstractions. "Gramsci understood that as soon as these concepts have to be applied 
to specific historical social formations ... the theorist is required to move from the level of 'mode of production' to a lower, more concrete, level of application" (414). Concreteness, in short, restored the historical materialism to Marx's method and, via the concept of articulation, made it possible to take specific forms of power like racism into account in any analysis of capitalism, and vice versa.

As Nick Couldry points out in relation to "connectionism," articulation's legacy in cyberculture studies, insisting on infinite forms of determination has limited use as a methodology, as it blocks attempts at "thinking concretely about what the complexity of culture might mean and how to investigate it" (Couldry, 2000: 94). And indeed, although the term articulation has become a crucial element of the vocabulary of cultural studies, it is by no means clear that anyone doing research on culture in the 1980s ever knew exactly how to translate it into a method, or a set of techniques. It is telling, indeed, that Slack's essay on "the theory and method of articulation" illustrates the concept's promise as a method by tracing how it might alter practices of theorizing communication (123-7). Janice Radway suggests that articulation might serve as the basis of a "reworked" ethnography, one that takes as its object not texts and their relations to readers, as her influential Reading the Romance did, but rather "the fluid process of articulation ... the process whereby the historical human subject is constructed through the linkage, clash, and confluence of many different discourses, practices, and activities. Such an ethnography would have to begin with the everyday, not with texts" (1996: 245). This proposal reinstates the ordinary in its return to the small scale of the everyday. However, it does not get at the more complexly scaled elements of articulation foregrounded by Hall, namely, the ways in which conjunctures are formed between different "levels" of social life.

This suggests that, rather than focus solely on one scale of existence, the individual, or the social group, or the practice of consumption, a methodology based on articulation would need a more mobile relationship to modes of abstraction and concreteness. But this recognition does not move the methodology much further toward a set of techniques. In a critique of the concept of articulation as a model for the political methodology of cultural studies, Tony Bennett (1996: 83) argues that the very "fluidity" of the process makes the praxis of cultural studies lean heavily toward discursive registers. This, he notes, is a big problem with the Gramscian tradition in cultural studies. Against the latter, which, in a somewhat idiosyncratic reading, he sees 
as locating its model of non-deterministic social relations in processes of representation, Bennett proposed a Foucauldian model, emphasizing the contingency of the social in material rather than discursive terms. This model, for Bennett, would better encourage "us to focus on the detailed routines and operating procedures of cultural institutions ... the business which culture is caught up in, looked at in these terms, goes beyond the influence of representations on forms of consciousness to include the influence of institutional practices, administrative routines and spatial arrangements on the available repertoires of human conduct and patterns of social interaction" (82). This proposal hearkened back to Williams's call for a sociology of culture; it took one step further in assigning a more active sense of praxis to the researcher, one that moved him or her beyond the world of representations and into the world of institutions.

Bennett's proposed application of Foucault as a model of praxis, offered in response to the discursivity of articulation theory, was part of a broader push toward cultural policy, as a way of rethinking political praxis in cultural studies (Bennett, 1998: 7; O'Regan, 1993; Cunningham, 1992). Like articulation theory, it emerged in dialog with state and governmental power structures in a particular national context. But whereas the former responded to the political problem of Thatcherism, cultural policy emerged from a politically progressive national context, specifically, the governmental initiatives in culture associated with the uninterrupted rule of the Labor Party in Australia from 1983 to 1996 . The arguments for cultural policy advocacy as the proper work of cultural studies reunited the concrete and the ordinary, but not as a return to the originary white working-class ordinary. Using Foucault's later work (1979/2001) on governmentality as a model, Bennett, Ian Hunter, and others shifted the locus of ordinariness from the object of cultural studies research to the identity of the researcher. It was no longer radical to study the ordinary and the insignificant, bringing popular culture in all its microbial forms into the academy. Rather, the policy advocates suggested, the radical gesture was to be ordinary and insignificant, assuming the modest, practical guise of the government worker (Bennett, 1992, quoted in O'Regan, 1993: 195). The movement's political potential, they suggested, lay not in terms of its ability to produce cultural critique, even if it did so in the service of ordinary, small-scale forms of everyday culture, but rather in its ability to be ordinary, instrumental, "hooked in" with institutions rather than disdainfully condemning them and their mana- 
gerial populations from an illusory position of transcendence. Cultural studies practitioners were the ones who needed to become ordinary, as ordinary as the material, organizational social networks in which culture is produced, regulated, disseminated, and reformed. The bureaucrat, Morris (1992: 466) notes, became cultural studies' ideal figure.

This cultural policy "push" in Australian scholarship was a materialist intervention in that it sought to ground the history of the study of culture in modes of governance. The progressive political value of such a move, according to Ian Hunter, was that it broke with what he saw as the romantic, aesthetic approach to culture, implicitly predicated on a separation of intellectuals from the object of study, whether in the service of contemplative disinterest or dialectical withdrawal: "the imperative to abstain from direct political activity until the reconciliatory moment of the dialectic brings the time to ripeness." Using work by Terry Eagleton as an example, Hunter (1992: 355) suggests that "the notion that the work of art cannot be known directly and definitively finds its correlate in the idea that society cannot be immediately subjected to administrative reason and intervention." In arguing that cultural studies' methods needed to mirror the concrete and pragmatic work of the cultural technician, Hunter and others invoked a politics of scale as they sought to redirect the movement away from "ethical grandiloquence, in which massive, world-historical problems are debated on such a level of generality that they cannot possibly be solved, and posed in ways which do not, will not, and cannot ever connect to agencies by which actual social futures may be given a "definite shape", (Morris, ibid.). In other words, the policy advocates inverted the sense of scale on which understandings of politics and methodology were predicated. Becoming banal, in short, was a way to avoid the "banality of cultural studies" that Morris, in an oft-cited zinger, defined as the endless repetition of statements about culture as "complex and contradictory" (Morris, 1990: 24).

As O'Regan notes, the acrimonious, either/or tenor of the policy intervention in cultural studies methods was to a large degree a reflection of institutional circumstances in higher education at that moment in Australia, "where the injunction to be socially relevant has been given a significant, alternative, and much more specific ... definition" by virtue of an increasing movement toward economic rationalization in the formation of cultural policy (197). O'Regan himself ultimately refused to accept the either/or terms wholeheartedly, proposing instead "an alternative view of policy," or a Latourian tone in which policy is 
understood as "information handling" (199). Rather than merely reversing the positions occupied by cultural critique and cultural policy on the hierarchical scale of political relevance, and determinism, as Bennett and others had sought to do, O'Regan rejected this order of scale altogether, noting

I don't think policy... is the structural engine room which powers everything else. Policy is a particular kind of informational practice with its own limitations, potentialities, and linkages to other kinds of public discourse, including cultural criticism and journalism, over which it holds no necessary pre-eminence. (ibid.)

In this move, O'Regan proposed an even more radical understanding of policy as ordinary, and of the politics underlying methodological choices as contingent upon concrete circumstances: "there are no a priori principles for choosing policy over cultural criticism. Nor can any presumption be made about social utility and effectiveness as necessarily belonging to one or the other" (201). In this call for a pragmatic sense of cultural studies as a field of social actions, O'Regan radically relativizes the scale of cultural studies, seeing it as one among many forms of knowledge work carried out on the small-scale world of governmental institutions. O'Regan's call for a pragmatic and flexible, rather than doctrinaire, understanding of cultural policy work is an important move, as it initiates a convergence between the theory of articulation as a social process and the practice of cultural policy work. Both refuse the "macro" perspective and insist that intellectual practices "articulate" with other practices in a broader cultural plane. Toby Miller, translating this mandate into a blueprint for approaching particular cultural texts, characterizes this method as the analysis of cultural citizenship produced "where the popular and the civic brush up against one another" (1998: 4). In such formulations, a sense of the importance of specific moments of articulation in defining the project of cultural studies as a form of civic practice returns.

In conclusion, I want to ask how this persistent interest in situating the work of cultural studies within increasingly material frames of reference leads, perhaps inexorably, to a more relativist and material understanding of higher education as both a professional sphere and a workplace. This entails, I suggest, a reprise of ordinariness as a concept in cultural studies' intellectual activism. 


\section{Conclusion: Academic Labor as Ordinary Work}

Policy studies' recognition of the work of professional academics as existing on a continuum with other, governmental modes of knowledge work is evident in one current focus of intellectual activism in the United States: responses to the apparent rise of the "corporate university." Invigorated by recent National Labor Review Board (NLRB) decisions sanctioning graduate student labor organizing at private institutions, a movement is emerging based on the managerial, governmental functions of the professoriate. A large part of this movement is predicated upon the unavoidable recognition of the university's increasing dependence on a pool of flexible, temporary, underremunerated laborers in an ever-expanding set of euphemistic employment categories. In the words of adjunct faculty organizer Vincent Tirelli (1998: 181), "the nation's higher education faculty have not been immune to the trend toward low-paying, part-time, and temporary work." If ideologies of the distinctiveness of academic work practices often rest on hierarchical scale models of meritocracy and apprenticeship, then one aspect of the call for equitable labor practices in higher education is the replacement of these models with a more transparent one, in which academic labor exists on a continuum with, rather than to the side of, other forms of "ordinary" work (Juffer, 2001: 268-70; Tirelli, 1998: 193-4). The difficulty in organizing around this idea lies, Andrew Ross (2000: 6-7) notes, in the fact that the production of culture, whether by educators or artists, is a form of labor traditionally discounted by those selling it. The problem, he suggests, is that "artistic and academic traditions extol sacrificial concepts of mental or cultural labor that are increasingly vital to newly important sectors of the knowledge industries. No longer on the margins of society, in Bohemia or the Ivory Tower, they are providing a rationale for the latest model of labor exploitation in core sectors of the new industrial order, and pioneering the workplace of tomorrow" (2). Cultural studies at this particular moment is, interestingly, less affected by these changes than the disciplines are, given that the highest levels of exploitation can be found in the disciplines and vocational sectors of the institution rather than in cultural studies per se. Cultural studies is not part of the education production line staffed by adjuncts and graduate student employees at the American university; rather, this line is made up of teachers of languages including "English as a Second Language," music, 
written composition, media production, and continuing education the latter an extremely lucrative source of income for large private urban universities. Yet at the same time, as was the case with cultural studies, these "extramural" sites of higher education, the university's "outposts" marking the points where it meets the world beyond the campus, serve as the locus for new forms of political action and radical thought.

A recent article by Jane Juffer (2001) demonstrates the ongoing importance of close reflection upon the methodological assumptions underlying critiques of the political economy of higher education. Orders of scale, she implies, remain relevant to the politicized work of cultural studies within the disciplines. As a critique of the critics of the corporate university, the essay exemplifies the ongoing relevance of articulation, in the sense of awareness of the linkages formed at concrete historical moments, as a first principle of intellectual activism. Detailing the contradictions and obstacles facing Latino studies in this moment in higher education, Juffer asks what kinds of intellectual practice Latino/a cultural studies should adopt, to best serve students whose entry into the university, after all, is made possible through corporate models of managed diversity - models in which "diversity" serves the purposes of job training in multiple dimensions. Many critics bemoan the corporatization of higher education. But, under current conditions, Juffer asks, is an abstracted understanding of culture as "a space of opposition that is most effective when it is pure" (268) the best place from which to launch a critique? After all, many critiques betray a nostalgia for a past when it was possible to believe that the university was free from the contamination of the market (and, she implies, the people who came in with the market.) In these critiques, "as in corporate diversity discourse ... the subject is granted an autonomy which exceeds material conditions, indeed, in which material conditions are assumed to be impediments to truth" (285). Both the sacrificial model of academic labor as a vocational calling and the purist model of liberal culture as resistance to commodification are abstractions that conceal their origins in the material conditions of the university as an institution. Rather than mount an activist politics on this basis, Juffer calls for a practice of Latino cultural studies in the institution which acknowledges "the corporate university's material commitments" rather than disdaining them, "and hence the students and faculty who gained entry on the basis of these commitments" (285; cf. Miller, 2003). In arguing for a model of academic work that accepts the idea 
of the professor as manager, and which tries to actualize the political agency within this identity, Juffer demonstrates the continued relevance of ordinariness as a "civic virtue" more valuable than liberal exceptionalism in cultural studies.

Juffer's remarks illustrate the continued need for cultural studies to reflect on the political assumptions underlying judgments of ordinariness and transcendence. Encoded in the phrase "Culture is Ordinary" is the imperative to understand the work of the scholar as part of a tradition of ordinary practices in cultural labor - teaching, reform, activism, policy work, administration. Increasingly, I have tried to show, cultural studies is itself ordinary. Political activism in the academy, whether it calls itself cultural studies or not, can draw on this sense of ordinariness as a methodological resource that focuses attention on the material conditions of knowledge production, and guards against the easy acceptance of foundational abstractions. Although "cultural studies" may not always matter very much as a discipline or a single, coherent set of research techniques, its methodological insistence on situating knowledge production within the concrete, small-scale world of everyday life, from spaces of leisure to the workaday world of institutions, ensures its continued relevance for political reflection within higher education.

\section{Notes}

1 The illuminating work on the politics of scale in the discipline of geography lie outside the confines of this essay. However, I must note that my own thinking on this issue is strongly influenced by the work of geographers, particularly the writings of Doreen Massey (1994), Neil Smith (1992), and David Harvey (1996). For an excellent overview, written by a geographer specializing in media, of the ways that scale has shaped thinking on media and politics see Clive Barnett, "Neither Poison nor Cure: Space, Scale, and Public Life in Media Theory" in Nick Couldry and Anna McCarthy (eds.), MediaSpace: Place, Scale, and Culture in a Media Age (London: Routledge, 2004). An account of the conceptual work of scale in cultural research would look differently again were it written from the disciplinary perspective of anthropology - a point raised collectively by Birgit Meyer, Charles Hirschkind, Mattijs van der Poort and Steve Hughes in response to a draft of this paper presented at the Research Centre in Religion and Society, Department of Sociology and Anthropology, University of Amsterdam in 2003. Their generous feedback is much appreciated; any errors in the essay are my own.

2 We can see evidence of cultural studies' status as a "formation" rather than a coherent discipline in the fact that many of the cultural studies researchers who made important contributions to ethnographic studies of audiences have not continued 
in ethnography. The historical and geographical moment within which such audience studies took shape has been succeeded by a different set of political agendas. The work of David Morley is emblematic in this regard. One can trace a research arc from his classic Nationwide audience study, published at the beginning of Thatcher's prime ministership in 1980, to the more recent Spaces of Identity co-authored with Kevin Robins, a study of the role of media in the formation of national identities in Europe at the threshold of union. This shift in emphasis corresponds closely to the changing political questions facing British, and later European, subjects in this period.

3 The need to situate methodology within an order of scale that includes the conditions of knowledge production in the academy is easily grasped when one considers that a contradictory set of class relationships can be shored up under the methodological rubric of interdisciplinarity. On the one hand, the faint outline of a "global subject" comes into view in the ideal inter- or un-disciplinary bricoleur of cultural studies, described by some as a figure possessing the ability and resources - or "charismatic authority" (Bennett, 1998: 58) - to rise above disciplines and their methods. There may be an institutional division within the profession, at least in the United States, between those who are interdisciplinary and those who, for reasons that might have a lot to do with teaching demands, curricula, tenure status etc., are not. But, on the other hand, interdisciplinarity describes a relationship to the institution which is in no sense a "rising above." In postwar Britain, cultural studies' interdisciplinarity reflected the marginal class and institutional status of those scholars, like Hoggart and Williams, who shaped its emergence (Gibson and McHoul, 2001: 24-5). In the United States, the kinds of academic appointments that institutionalize interdisciplinarity are fraught with problems of workload and performance evaluation. Most obviously, people who work in women's studies, black studies, and various area studies often hold joint appointments in one or more departments and/or "programs," a situation which can double the amount of service work and administration one must do, to say nothing of the thorny promotion and retention issues involved in navigating not only more than one departmental "culture," but also the concerns of more than one professional audience for one's work (Wissoker, 2000). Methodologies are as shaped by these circumstances as they are by the questions being posed by the historical moment.

\section{References}

Barnett, C. (2004) "Neither Poison nor Cure: Space, Scale, and Public Life in Media Theory," in Nick Couldry and Anna McCarthy (eds.), MediaSpace: Place, Scale, and Culture in a Media Age (London: Routledge), pp. 58-74.

Bennett, T. (1992) "Putting Policy into Cultural Studies," in Grossberg et al. (eds.), Cultural Studies (New York: Routledge), pp. 23-33.

Bennett, T. (1998) Culture: a Reformer's Science (London and Thousand Oaks, CA: Sage Publications).

Brunsdon, C. (1996) "A Thief in the Night: Stories of Feminism in the 1970s at CCCS," in David Morley and Kuan-Hsing Chen (eds.), Stuart Hall: Critical Dialogues in Cultural Studies (London: Routledge), pp. 276-86. 


\section{Cultural Studies and the Politics of Scale}

Brunsdon, C. (1999) The Feminist, the Housewife, and the Soap Opera (New York: Oxford University Press).

Brunsdon, C., C. Johnson, R. Moseley and H. Wheatley (2001) "Factual Entertainment on British Television: the Midlands TV Research Group's '8-9 Project'," European Journal of Cultural Studies, 4(1): 29-62.

Burke, Peter (ed.) (2001) New Perspectives on Historical Writing (University Park, PA: Pennsylvania State University Press).

Carby, H. (1982/1996) "White Woman Listen! Black Feminism and the Boundaries of Sisterhood," in Houston A. Baker Jr. et al., Black British Cultural Studies: A Reader (Chicago: University of Chicago Press), pp. 61-86.

Couldry, N. (2000) Inside Culture: Re-imagining the Method of Cultural Studies (London and Thousand Oaks, CA: Sage Publications).

Cunningham, S. (1992) Framing Culture: Criticism and Policy in Australia (North Sydney, NSW, Australia: Allen \& Unwin).

Dworkin, D. (1997) Cultural Marxism in Postwar Britain: History, the New Left, and the Origins of Cultural Studies (Durham, NC: Duke University Press).

Foucault, M. (1970) The Order of Things: An Archaeology of the Human Sciences (New York: Vintage Books).

Foucault, M. (1979/2001) “On Governmentality,” in Michel Foucault, James D. Faubion et al., Power: Essential Works of Foucault, 1954-1984, vol. 3 (New York: The New Press), pp. 201-22.

Garnham, N. (1995) "Political Economy and Cultural Studies: Reconciliation or Divorce?," Critical Studies in Mass Communication, 12(1): 62-71.

Giard, L. (1998) "Introduction," in Michel de Certeau, Luce Giard, and Olivier Meyrol, The Practice Of Everyday Life, vol 2: Eating and Cooking (Minneapolis: University of Minnesota Press).

Gibson, M. and A. McHoul (2001) "Interdisciplinarity," in Toby Miller (ed.), $A$ Companion to Cultural Studies (Cambridge, MA: Blackwell), pp. 23-35.

Gibson-Graham, J.K. (1996) The End of Capitalism (As We Knew It): a Feminist Critique of Political Economy (Cambridge, MA: Blackwell Publishers).

Ginzburg, C. (1980) The Cheese and the Worms: the Cosmos of a Sixteenth-Century Miller, trans. John and Anne Tedeschi (Baltimore: Johns Hopkins University Press).

Grossberg, L. (1996) "On Postmodernism and Articulation: an Interview with Stuart Hall," in David Morley and Kuan-Hsing Chen (eds.), Stuart Hall: Critical Dialogues in Cultural Studies (London: Routledge), pp. 151-73.

Grossberg, L. (1997) Bringing it All Back Home: Essays on Cultural Studies (Durham, NC: Duke University Press).

Hall, S. (1980) "Cultural Studies: Two Paradigms," Media, Culture, and Society, 2: $57-72$.

Hall, S. (1980/1996) "Race, Articulation, and Societies Structured in Dominance," in Houston A. Baker Jr. et al., Black British Cultural Studies: A Reader (Chicago: University of Chicago Press), pp. 16-60.

Hall, Stuart. (1986/1996) "Gramsci's Relevance for the Study of Race and Ethnicity," in David Morley and Kuan-Hsing-Chen, Stuart Hall: Critical Dialogues in Cultural Studies (London: Routledge), pp. 411-40.

Hall, Stuart (1992) "Cultural Studies and Its Theoretical Legacies," in Grossberg et al. (eds.), Cultural Studies (New York: Routledge), pp. 277-94. 


\section{Anna McCarthy}

Hall, S., and Jefferson, T. (1976) Resistance Through Rituals: Youth Subcultures in Post-war Britain (London: Hutchinson).

Hartley, J. (1992) The Politics of Pictures: the Creation of the Public in the Age of Popular Media (London and New York: Routledge).

Hartley, J. (1999) The Uses of Television (London: Routledge).

Harvey, D. (1996) Justice, Nature and the Geography of Difference (Cambridge, MA: Blackwell).

Hebdige, D. (1979) Subculture: The Meaning of Style (London: Routledge).

Hoggart, R. (1998/1957) The Uses of Literacy (New Brunswick, NJ and London: Transaction Publishers).

Hunter, I. (1992) "Aesthetics and Cultural Studies," in Grossberg et al. (eds.), Cultural Studies (New York: Routledge), pp. 347-67.

Juffer, J. (2001). "The Limits of Culture: Latino Studies, Diversity Management, and the Corporate University," Nepantla, 2(2): 265-93.

Karsten, P. and J. Modell (eds.) (1992) Theory, Method, and Practice in Social and Cultural History (New York: New York University Press).

de Laet, M. (2001) "Notes on the Traffic between Cultural Studies and Science and Technology Studies," in Toby Miller (ed.), A Companion to Cultural Studies (Cambridge, MA: Blackwell), pp. 101-15.

Ma, E. (2001) "Peripheral Vision: Chinese Cultural Studies in Hong Kong," in Toby Miller (ed.), A Companion to Cultural Studies (Cambridge, MA: Blackwell), pp. 259-74.

Martin, R. (2001) "The Renewal of the Cultural in Sociology," in Toby Miller (ed.), A Companion to Cultural Studies (Cambridge, MA: Blackwell), pp. 63-78.

Marx, K. (1973) Grundrisse, trans. Ben Fowkes (London: Penguin Books).

Massey, D. (1994) Space, Place, and Gender (Minneapolis: University of Minnesota Press).

Maxwell, R. (2001) "Political Economy in Cultural Studies," in Toby Miller (ed.), $A$ Companion to Cultural Studies (Cambridge, MA: Blackwell), pp. 116-38.

Miller, T. (1998) Technologies of Truth: Cultural Citizenship and the Popular Media (Minneapolis: University of Minnesota Press).

Miller, T. (2001) "What it is and what it isn't: Introducing ...Cultural Studies," in Toby Miller (ed.), A Companion to Cultural Studies (Cambridge, MA: Blackwell), pp. 1-22.

Miller, T. (2003) “Governmentality or Commodification? US Higher Education,” Cultural Studies, 17(6): 897-904.

Morris, M. (1990) "Banality in Cultural Studies," in Patricia Mellencamp (ed.), Logics of Television Essays in Cultural Criticism (Bloomington: Indiana University Press), pp. 14-43.

Morris, M. (1992) "On the Beach," in Grossberg et al. (eds.), Cultural Studies. New York: Routledge, pp. 450-78.

Nelson, C. et al. (1992) "Cultural Studies: An Introduction," in Grossberg et al. (eds.), Cultural Studies (New York: Routledge), pp. 1-16.

O'Regan, T. (1993) “(Mis)taking Policy: Notes on the Cultural Policy Debate," in John Frow and Meaghan Morris (eds.), Australian Cultural Studies: A Reader. Urbana: University of Illinois Press: pp. 192-208. 
Oxford English Dictionary Second Edition (1989). Online (subscription only) at http: dictionary.oed.com.

Pines, J. (1996) "The Cultural Context of Black British Cinema," in Houston A. Baker Jr. et al., Black British Cultural Studies: A Reader (Chicago: University of Chicago Press), pp. 183-93.

Radway, J. (1996) "The Hegemony of Specificity and the Impasse in Audience Research," in James Hay, Lawrence Grossberg, and Ellen Wartella (eds.), The Audience and its Landscape (Boulder, CO: Westview Press), pp. 235-46.

Ross, A. (2000) “The Mental Labor Problem," Social Text, 18(2): 1-31.

Slack, J. (1996) "The Theory and Method of Articulation in Cultural Studies," in David Morley and Kuan-Hsing Chen (eds.), Stuart Hall: Critical Dialogues in Cultural Studies (London: Routledge), pp. 112-30.

Smith, N. (1992) "Contours of a Spatialized Politics: Homeless Vehicles and the Production of Geographic Scale," Social Text, 33: 55-81.

Stam, R. (2001) "Cultural Studies and Race," in Toby Miller (ed.), A Companion to Cultural Studies (Cambridge, MA: Blackwell), pp. 471-89.

Thompson, E.P. (1984) "Interview," in Henry Abelove (ed.), Visions of History (New York: Pantheon).

Tinkcom, M. (2002) Working Like a Homosexual: Camp, Capital, Cinema (Durham, NC: Duke University Press).

Tirelli, V. (1998) "Adjuncts and More Adjuncts: Labor Segmentation and the Transformation of Higher Education," in Randy Martin (ed.), Chalk Lines: The Politics of Work in the Managed University (Durham, NC: Duke University Press), pp. 181-201.

Webster, Frank (2001) "Sociology, Cultural Studies, and Disciplinary Boundaries," in Toby Miller (ed.), A Companion to Cultural Studies (Cambridge, MA: Blackwell), pp. 79-100.

Williams, R. (1958) Culture and Society, 1780-1950 (London: Chatto \& Windus).

Williams, R. (1976) Keywords: a Vocabulary of Culture and Society (New York: Oxford University Press).

Williams, R. (1977) Marxism and Literature (New York: Oxford University Press).

Willis, P. (1980) "Notes on Method," in S. Hall, D. Dobson, and P. Willis (eds.), Culture, Media and Language (London: Hutchinson), pp. 88-95.

Wissoker, K. (2000) "Negotiating a Passage Between Disciplinary Borders," Chronicle of Higher Education, April 14, p. B4. 